\title{
An Alternative Approach for Oil-immersed High Voltage Power Transformer Dissolved Gas Analysis Diagnostic Techniques
}

\author{
Ahmad Karimi Mehrabadi, Asaad Shemshadi* and Hossein Shateri \\ Department of Electrical engineering. \\ Arak University of Technology, Arak, Iran.
}

*Corresponding author: shemshadi@ arakut.ac.ir, Tel: +9833400615, Fax: +988633670020

\begin{abstract}
This article presents alternative analyzing method of extracted dissolved gases related to insulating oil of power transformers. Analysis of soluble and free gas is one of the most commonly used troubleshooting methods for detecting and evaluating equipment damage. Although the analysis of oil-soluble gases is often complex, it should be expertly processed during maintenance operation. The destruction of the transformer oil will produce some hydrocarbon type gases. The development of this index is based on two examples of traditional evaluation algorithms along with fuzzy logic inference engine. Through simulation process, the results of the initial fractures in the transformer are obtained in two ways by the "Duval Triangle method" and "Rogers's ratios". In continue, three digit codes containing the fault information are created based on the fuzzy logic inference engine to achieve better results and eliminate ambiguous zones in commonly used methods, especially in the "Duval Triangle method". The proposed method is applied to 80 real transformers to diagnose the fault by analyzing the dissolved oil based on fuzzy logic. The results illustrate the proficiency of this alternative proposed algorithm. Finally, with utilization of a neural network the alternative practical inference function is derived to make the algorithm more usable in the online condition monitoring of power transformers.
\end{abstract}

Keywords: Power transformer, Fault diagnosis, DGA, Fuzzy Logic, neural network..

(C) 2019 Penerbit UTM Press. All rights reserved

Article History: received 12 December 2018; accepted 16 June 2019; published 31 August 2019.

\section{INTRODUCTION}

Transformers are one of the primary electrical systems for converting the voltage levels in a power system. Power transformers are the most expensive apparatus in a typical power system network. So, every effort related to monitoring the live operational conditions of this equipment is very important in order to diagnose and prevent major defects inside the equipment on time. In the other hand nonchalance in the diagnostic process brings to sudden failure in transmission of electrical energy to the power network which may reduce the reliability factor of the system and lead to huge economic losses. [1-8]. so scheduled controls are needed for a typical power transformers transformer [9-12]. Regarding to previous tasks insulation properties failure are the main reason for most equipment break down, insulating mineral oil (IMO) is the main insulator medium in an oil immersed power transformer type. Since 1960, some methods have been developed based on analyzing the dissolved gases extracted from operating transformer oil, the inference methods like Duvall triangle method, Rogers ratio method, IEC 60599 standard, etc. are practical based and so non zero uncertainty should be considered [13-16].

This article is prepared to reduce the amount of uncertainty factor related to fault prediction with utilization of two most popular DGA methods. Furthermore some ambiguous zones regarding to the Duvall triangle method, are cleared in this alternative approach. In continue of this work; three and four digit codes containing the fault information are created based on the fuzzy logic engine to enhance the final results. The method is applied to 80 real transformers in Iran to diagnose the fault by analyzing the dissolved oil based on fuzzy logic and is approximated using the neural network [17-21]. Finally a mathematical approximated formula is derived with utilization of a proper feed forward perceptron neural network to make this alternative DGA technique more applicable in the common distributed control system (DCS) soft wares of the alternative installed high voltage power substations.

\section{HISTORY OF DGA}

The ratio of dissolved gases for the diagnostic process was first used by Mr. Dannenberg in 1970 to distinguish between electrical and thermal imperfections using six major dissolved gases and arranging four gas ratios [2] After him, Rogers, inspired by the Thermodynamics Model, proposed the Roger's ratio method in 1973 [3], the method was improved in 1975 and 1977 consequently [4]. This theory was experimented frequently since 1978 in the laboratory researches, industrial tests, etc. in continue this method with minor changes was changed to 
IEC 60599 standard method. It is important to note that gas value detector in all methods is gas chromatography device. Table 1 demonstrates common power transformer faults and the real examples. For example thermal faults above $700{ }^{\circ} \mathrm{C}$ may be occurred by a large circulation current in thank and core.

Table 1. Typical faults and reasons in a typical power transformers

\begin{tabular}{|c|c|}
\hline Fault & Examples \\
\hline $\begin{array}{c}\text { Partial } \\
\text { discharges }\end{array}$ & $\begin{array}{l}\text { Discharges in gas-filled cavities resulting } \\
\text { from incomplete impregnation, high } \\
\text { humidity in paper, oil super saturation or } \\
\text { cavitation. }\end{array}$ \\
\hline $\begin{array}{l}\text { low energy } \\
\text { discharges }\end{array}$ & $\begin{array}{l}\text { Sparking or arcing between bad } \\
\text { connections of different or floating } \\
\text { potential, from shielding rings, toroid, } \\
\text { adjacent disks or conductors of winding, } \\
\text { broken brazing or closed loops in the core } \\
\text { Discharges between clamping parts, } \\
\text { bushing and tank. }\end{array}$ \\
\hline $\begin{array}{c}\text { high energy } \\
\text { Discharges }\end{array}$ & $\begin{array}{l}\text { Flashover, tracking, or arcing of high } \\
\text { local energy or with power follow- } \\
\text { through Short circuits between low } \\
\text { voltage and ground, connectors, windings, } \\
\text { bushings and tank, copper bus and tank, } \\
\text { windings and core, in oil duct, turret. } \\
\text { Closed loops between two adjacent } \\
\text { conductors. }\end{array}$ \\
\hline $\begin{array}{c}\text { Thermal } \\
\text { fault } \\
t<300{ }^{\circ} \mathrm{C}\end{array}$ & $\begin{array}{l}\text { Overloading of the transformer in } \\
\text { emergency } \\
\text { Blocked item restricting oil flow in } \\
\text { windings } \\
\text { Stray flux in clamping beams of yokes. }\end{array}$ \\
\hline $\begin{array}{l}\text { Thermal } \\
\text { fault } \\
300{ }^{\circ} \mathrm{C}<t \\
<700{ }^{\circ} \mathrm{C}\end{array}$ & $\begin{array}{l}\text { Circulating currents between yoke clamps } \\
\text { and bolts, clamps and laminations, in } \\
\text { ground wiring, defective welds or clamps } \\
\text { in magnetic shields abraded insulation } \\
\text { between adjacent parallel conductors in } \\
\text { windings. }\end{array}$ \\
\hline $\begin{array}{l}\text { Thermal } \\
\text { fault } \\
t>\mathbf{7 0 0}^{\circ} \mathrm{C}\end{array}$ & $\begin{array}{l}\text { Major defect in transformer. Large } \\
\text { circulating currents in tank and core, } \\
\text { Minor circulation currents in tank walls } \\
\text { created by a high uncompensated } \\
\text { magnetic field }\end{array}$ \\
\hline
\end{tabular}

\subsection{Doernengburg Ratio Method}

The diagnostic theories use a set of combustible key gas ratios based on the dissolution principles as error indicators. These five ratios are as below:

Ratio $1(\mathrm{R} 1)=\mathrm{CH}_{4} / \mathrm{H}_{2}$

Ratio 2 (R2) $=\mathrm{C}_{2} \mathrm{H}_{2} / \mathrm{C}_{2} \mathrm{H}_{4}$

Ratio $3(\mathrm{R} 3)=\mathrm{C}_{2} \mathrm{H}_{2} / \mathrm{CH}_{4}$

Ratio 4 (R4) $=\mathrm{C}_{2} \mathrm{H}_{6} / \mathrm{C}_{2} \mathrm{H}_{2}$

Ratio $5(\mathrm{R} 5)=\mathrm{C}_{2} \mathrm{H}_{4} / \mathrm{C}_{2} \mathrm{H}_{6}$

The Dorenberg ratio method is so performed that utilizes ratios $1,2,3$, and 4 . This method requires a significant level of gases to identify the method's validity.

The ratios should be compared to $1,2,3$, and 4 and the constrained values, and the proposed error detection is presented in accordance with

Table 2.

Table 2 shows the limiting values of the ratio of gases dissolved in oil regarding to dorenberg diagnostic method.[8].the numbers in this table show the ratio of obtaind gases.

Table 2. Ratios for key gases-Doernenburg method

\begin{tabular}{|c|c|c|c|c|c|c|c|c|}
\hline \multirow{2}{*}{$\begin{array}{l}\text { Suggested } \\
\text { fault } \\
\text { diagnosis }\end{array}$} & \multicolumn{2}{|c|}{$\approx \underset{\Xi}{ت}$} & \multicolumn{2}{|c|}{ 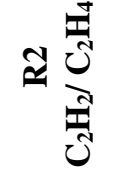 } & \multicolumn{2}{|c|}{ 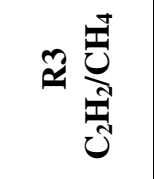 } & \multicolumn{2}{|c|}{ 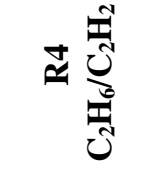 } \\
\hline & $\overline{0}$ & $\begin{array}{c}\tilde{E} \\
\tilde{\tilde{E}} \\
\text { की }\end{array}$ & $\bar{\sigma}$ & $\begin{array}{l}\tilde{\tilde{\sigma}} \\
\tilde{\tilde{n}} \\
\tilde{n} \\
\tilde{0}\end{array}$ & $\overline{0}$ & 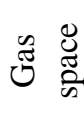 & $\bar{\sigma}$ & 芯 \\
\hline $\begin{array}{l}\text { Thermal } \\
\text { decomposi } \\
\text { tion }\end{array}$ & $\frac{0}{\lambda}$ & $\overrightarrow{0}$ & $\stackrel{n}{\stackrel{0}{v}}$ & $\frac{O}{\vec{v}}$ & $\stackrel{?}{\vec{v}}$ & $\overrightarrow{\dot{v}}$ & $\underset{0}{\dot{0}}$ & 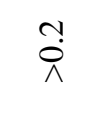 \\
\hline $\begin{array}{l}\text { low- } \\
\text { intensity } \\
\text { PD }\end{array}$ & $\overrightarrow{\dot{v}}$ & $\begin{array}{l}\overrightarrow{0} \\
\dot{0}\end{array}$ & i & $\stackrel{n}{\hat{v}}$ & $\vec{\nabla}$ & $\stackrel{+}{\stackrel{0}{0}}$ & 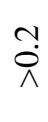 & \\
\hline $\begin{array}{l}\text { Arcing } \\
\text { (high } \\
\text { intensity) }\end{array}$ & $\begin{array}{l}\vec{v} \\
\vec{a} \\
\underline{v} \\
\frac{1}{0}\end{array}$ & $\frac{\frac{v}{\sigma}}{\frac{v}{v}}=$ & $\stackrel{n}{\mathfrak{r}}$ & $\frac{0}{\lambda}$ & $\hat{గ}$ & $\overrightarrow{0}$ & $\stackrel{+}{\vec{V}}$ & 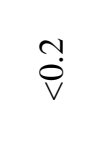 \\
\hline
\end{tabular}

\subsection{Roger's Ratio Method}

Table 3, show Rogers ratio according to ref. 8 . with utilization of three gas ratios as $\mathrm{C} 2 \mathrm{H} 2 / \mathrm{C} 2 \mathrm{H} 4, \mathrm{CH} 4 / \mathrm{H} 2$ and $\mathrm{C} 2 \mathrm{H} 4 / \mathrm{C} 2 \mathrm{H} 6$ to indicate four possible faults diagnostic conditions as normal unit, low energy density and arcing PD, arcing high energy discharge, and low temperature thermal fault. Figure 1 demonstrates fuzzy type membership functions for three input ratios of gases and output result that accord with Roger's ratio method. The numbers in table 3 show the ratio of extracted gases ratios.

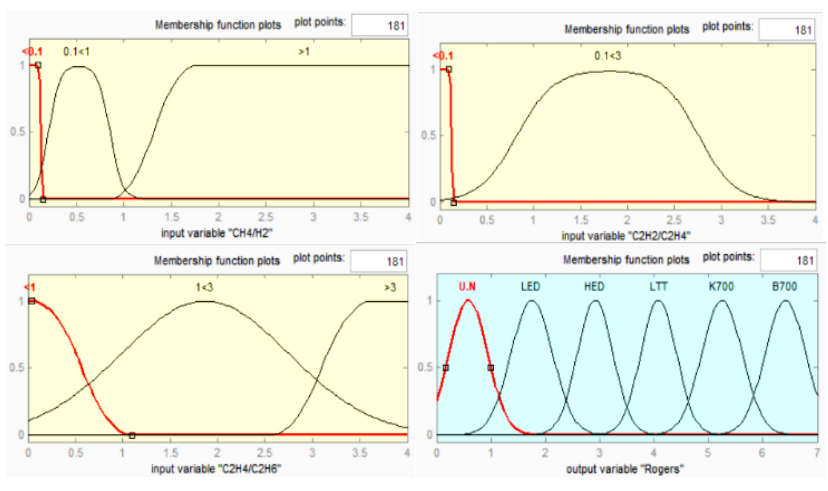

Figure 1. Membership functions of input and output variables Rogers fuzzy system paper 
Table 3 DGA corresponding to Rogers's ratios

\begin{tabular}{|c|c|c|c|c|c|}
\hline $\begin{array}{l}\tilde{E} \\
\tilde{\Xi} \\
\tilde{U}\end{array}$ & 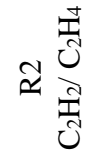 & 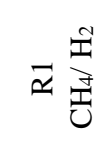 & 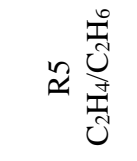 & 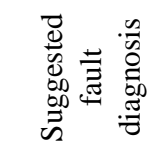 & 勇 \\
\hline 0 & $<0.1$ & $\begin{array}{c}>0.1 \text { to } \\
1.0\end{array}$ & $<1.0$ & $\begin{array}{c}\text { Unit } \\
\text { normal }\end{array}$ & 012 \\
\hline 1 & $<0.1$ & $<0.1$ & $<1.0$ & $\begin{array}{c}\text { Low } \\
\text { energy } \\
\text { density } \\
\text { arcing PD }\end{array}$ & 002 \\
\hline 2 & $\begin{array}{c}0.1 \text { to } \\
3.0\end{array}$ & $\begin{array}{c}0.1 \text { to } \\
1.0\end{array}$ & $>3.0$ & $\begin{array}{l}\text { Arcing } \\
\text { High } \\
\text { energy } \\
\text { discharge }\end{array}$ & 213 \\
\hline 3 & $<0.1$ & $\begin{array}{c}>0.1 \text { to } \\
<1.0\end{array}$ & 1.0 to 3.0 & $\begin{array}{l}\text { Low } \\
\text { temperature } \\
\text { thermal }\end{array}$ & 012 \\
\hline 4 & $<0.1$ & $>1.0$ & 1.0 to 3.0 & $\begin{array}{c}\text { Thermal } \\
<700^{\circ} \mathrm{C}\end{array}$ & 022 \\
\hline 5 & $<0.1$ & $>1.0$ & $>3.0$ & $\begin{array}{l}\text { Thermal } \\
>700^{\circ} \mathrm{C}\end{array}$ & 023 \\
\hline
\end{tabular}

\subsection{IEC 60599 Standard Method}

This method is an alternative enhanced algorithm based on the Rogers ratio method, except that the ratio of $\mathrm{C}_{2} \mathrm{H}_{6} /$ $\mathrm{CH}_{4}$ is lost because it only represents the temperature range in the decomposition shown in Error! Reference source not found. In this method, errors are divided into six different types. The numbers in table 4 show gas ratios which are used during diagnostic process.

Table 4. IEC 60599 standard method

\begin{tabular}{|c|c|c|c|c|}
\hline Case & Faults & $\begin{array}{l}\mathrm{C}_{2} \mathrm{H}_{2} / \\
\mathrm{C}_{2} \mathrm{H}_{4} \\
\end{array}$ & $\begin{array}{c}\mathrm{CH}_{4} / \\
\mathrm{H}_{2}\end{array}$ & $\begin{array}{c}\mathrm{C}_{2} \mathrm{H}_{4} / \mathrm{C}_{2} \\
\mathrm{H}_{6}\end{array}$ \\
\hline PD & $\begin{array}{c}\text { Partial } \\
\text { Discharge }\end{array}$ & $\sim 0$ & $<0.1$ & $<0.2$ \\
\hline D1 & $\begin{array}{c}\text { Discharges } \\
\text { of low } \\
\text { energy }\end{array}$ & $>1$ & $0.1-0.5$ & $>1$ \\
\hline D2 & $\begin{array}{c}\text { Discharges } \\
\text { of High } \\
\text { Energy }\end{array}$ & $0.6-2.5$ & $0.1-1.0$ & $>2$ \\
\hline T1 & $\begin{array}{c}\text { Thermal } \\
\text { Fault }\end{array}$ & $\sim 0$ & $>1$ & $<1$ \\
\hline $\mathbf{T 2}$ & $\begin{array}{c}\text { Thermal } \\
\text { Fault }\end{array}$ & $<0.1$ & $>1$ & $<1$ \\
\hline T3 & $\begin{array}{c}\text { Thermal } \\
\text { Fault }\end{array}$ & $<0.2$ & $>1$ & $>4$ \\
\hline
\end{tabular}

\subsection{Duval Triangle Method}

This method has been used for many years even nowadays its popularity is increasing. The Duval triangle, as

shown

\section{in}

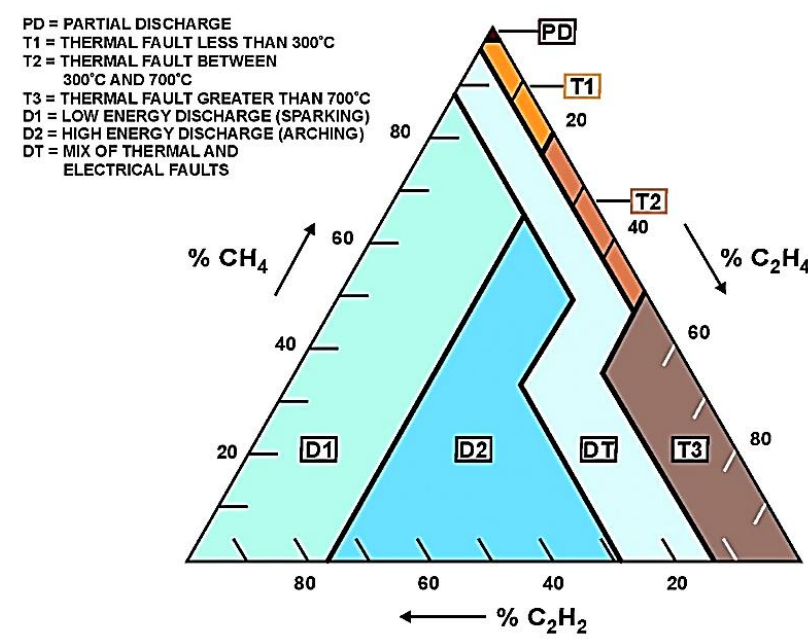

Figure 2, determines what type of internal fault is occurred inside the tank. In this method, three gases $\left(\mathrm{CH}_{4}, \quad \mathrm{C}_{2} \mathrm{H}_{2}, \quad \mathrm{C}_{2} \mathrm{H}_{4}\right)$ are utilized to initiate the investigation.[9]

To use the Duval method, refer to Table 4, which includes the minimum concentration of L1 gas in ppm and the gas production rate $\mathrm{G} 1$ and $\mathrm{G} 2$ both in ppm per month. Among all gases produced in oil, at least one gas must be equal to or greater than the values of L1, and the gas production rate is equal to or greater than $\mathrm{G} 2$. If the values are greater than G1, a warning signal is sent to the substation operator.

After all the conditions for using the method are met, the ratio of the percentage of each gas is calculated. To do this, the concentration of gas is divided by the total concentration of three gases in terms of concentration in ppm, as follows [9]:

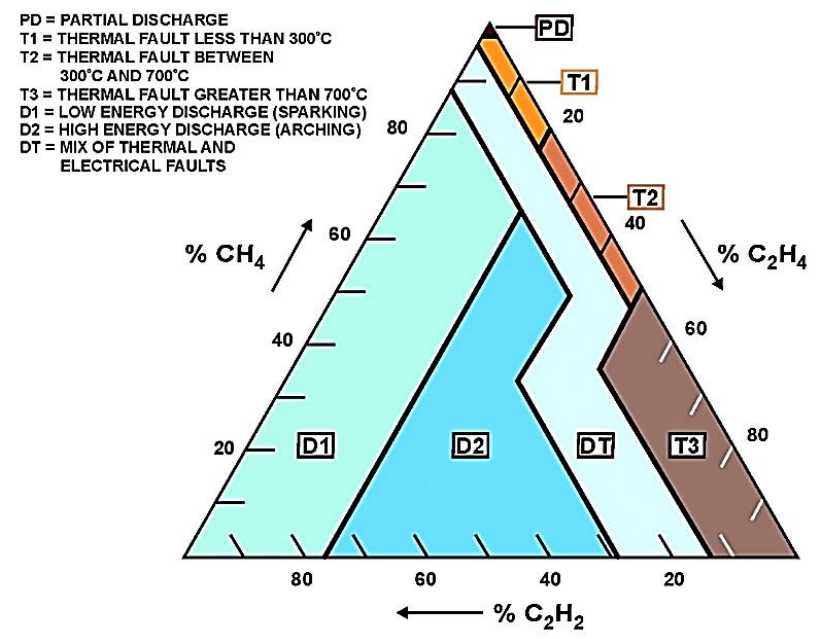

Figure 2. Duval triangle [10]

Table 4 . The range of oil gases and the range of gases produced per month (duval methode)

\begin{tabular}{|c|c|c|c|}
\hline Gas & L1(ppm) & $\begin{array}{c}\text { G1(ppm / } \\
\text { month) }\end{array}$ & $\begin{array}{c}\text { G2(ppm / } \\
\text { month) }\end{array}$ \\
\hline$H_{2}$ & 100 & 10 & 50 \\
\hline
\end{tabular}




\begin{tabular}{|c|c|c|c|}
\hline $\boldsymbol{C H}_{\boldsymbol{4}}$ & 75 & 8 & 38 \\
\hline $\boldsymbol{C}_{2} \boldsymbol{H}_{2}$ & 3 & 3 & 3 \\
\hline $\boldsymbol{C}_{2} \boldsymbol{H}_{\boldsymbol{4}}$ & 75 & 8 & 38 \\
\hline $\boldsymbol{C}_{2} \boldsymbol{H}_{\boldsymbol{6}}$ & 75 & 8 & 38 \\
\hline $\boldsymbol{C O}$ & 700 & 70 & 350 \\
\hline $\boldsymbol{C O}_{2}$ & 7000 & 700 & 3500 \\
\hline
\end{tabular}

$\% \mathrm{CH}_{4}=100 * \mathrm{P} 1 /(\mathrm{P} 1+\mathrm{P} 2+\mathrm{P} 3)$

$\% \mathrm{C}_{2} \mathrm{H}_{4}=100 * \mathrm{P} 2 /(\mathrm{P} 1+\mathrm{P} 2+\mathrm{P} 3)$

$\% \mathrm{C}_{2} \mathrm{H}_{2}=100 * \mathrm{P} 3 /(\mathrm{P} 1+\mathrm{P} 2+\mathrm{P} 3)$

To simplify the expressions, select $\mathrm{P} 1$ for methane gas $\left(\mathrm{CH}_{4}\right)$, P2 for ethylene $\left(\mathrm{C}_{2} \mathrm{H}_{4}\right)$ and P3 for acetylene $\left(\mathrm{C}_{2} \mathrm{H}_{2}\right)$.

Duval has three percentage rates of gas which can be utilized as fuzzy logic controller three inputs. Each entry membership functions required to achieve the Rules of proposed procedure and an output signal with seven bel shaped membership functions that indicates the type of diagnosed internal fault by Duval triangle is also defined.
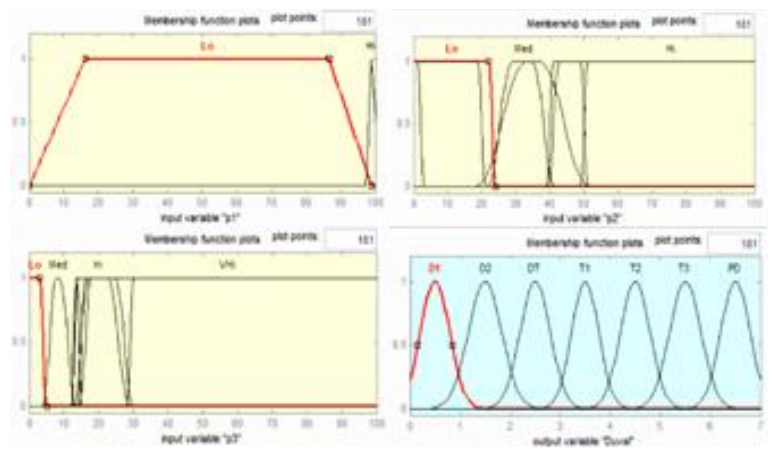

Figure 3. Membership functions of input and output variables regarding to duval triangular methode approximated by fuzzy inference engine.

\section{METHODOLOGY}

Each method of error detection has some advantages and limitations. The proposed alternative approach has been introduced to expand the method benefits and reduce constraints using fuzzy logic inference engine and neural network feed-forward tools to estimate the mathematical formula which easily indicates internal faults wit acceptable accuracy.

\subsection{Fuzzy Logic Inference Engine}

The proposed system is constructed by implementing a fuzzy logic inference engine set with three fuzzy logic subset controllers which combine two methods to obtain more precision and accuracy.

The alternative technique of the fuzzy system consists of three following steps:

The first alternative fuzzy controller, with the output of normal fuzzy controller constraints, has five inputs that contain five gases $\left(\mathrm{H}_{2}, \mathrm{CH}_{4}, \mathrm{C}_{2} \mathrm{H}_{6}, \mathrm{C}_{2} \mathrm{H}_{2}\right.$, and $\left.\mathrm{C} 2 \mathrm{H} 4\right)$ in ppm, and each input has two low and high membership functions for reaching the natural gas level. The limitations of gases in the duval triangle method are shown in Table 4, which we have defined with regard to other factors affecting the fuzzy network. The natural gas fuzzy controller has an output with two membership functions, which indicates the Normal and Fault are shown in Figure 4.

Each of the two fuzzy methods (Rogers and Duval triangle) receive five gas as inputs to deliver the results of their error type.

Consisting of a group of fuzzy controller with three inputs, two of them result from an error type of two fuzzy methods and its next input, the output of the fuzzy controller of the first stage, which indicates the error occurrence condition.

If the defect controller is in normal position, the output of the Rogers and Duval fuzzy systems will not be examined at all, and the final output will show normal mode; however, the output of those items will also be checked and displayed, and the probability of an error occurring at the output is also illuminated. But the final fuzzy engine at the last stage does not initiate a fault alarm.
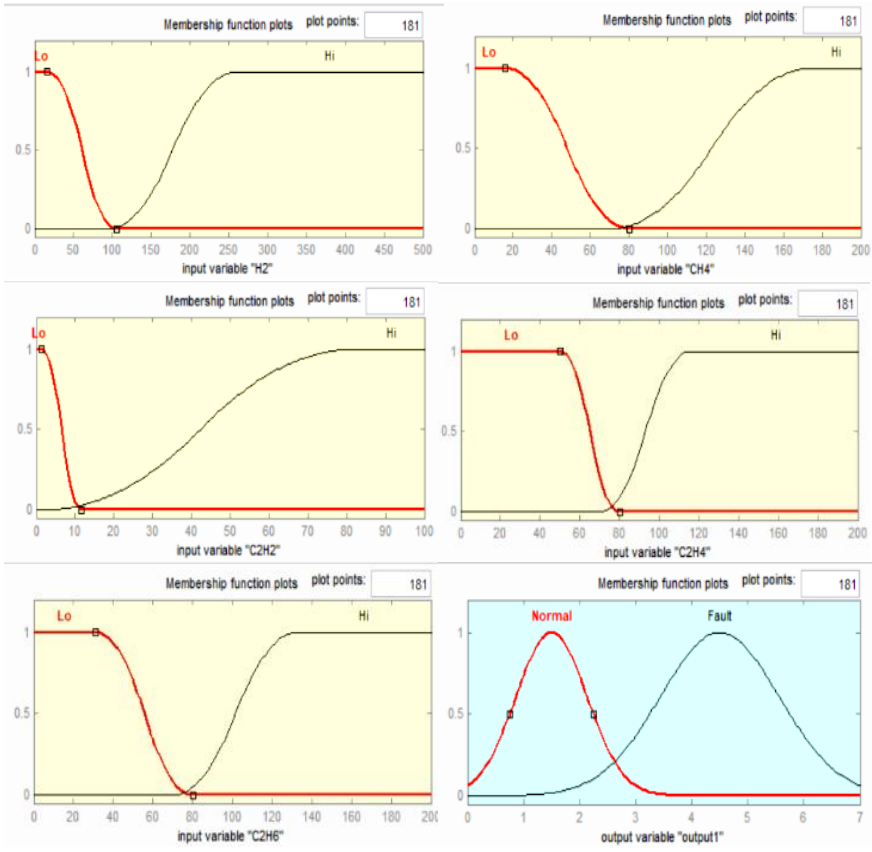

Figure 4. The membership functions of the input and output variables of the fuzzy diagnostic system

However, if the fault diagnostic controller is in error mode then the final fuzzy controller will examine the output of the two other fuzzy systems and, after examining the defined conditions, declares the type of error that is between 0 and seven, according to Figure 5 and the type of possible internal error in continue is detected.

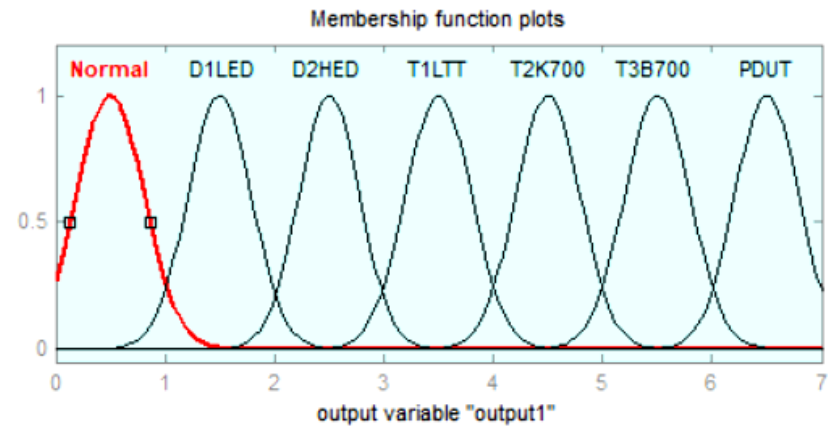


Figure 5. The final fuzzy system output membership functions

The fuzzy system is designed in MATLAB/Simulink as illustrated in Figure 6.

\subsection{Neural Network}

Since it was necessary to run the MATLAB program in order to run the fuzzy logic program, it looks like; better to approximate the mathematical transfer function using a proper neural network. After training and testing the neural network, we were able to obtain an equation for simple calculation of the output of a fuzzy system that can be interpreted and analyzed using Figure 5.

In addition to simplifying the diagnostic algorithm in a mathematical formula, makes it possible to use the designed alternative algorithm for the power industry on line monitoring soft wares.

Figure 7 illustrates the considered neural network structure Figure 8 shows a comparison between the actual values and predicted output of the neural network and Figure 9 shows neural network error.

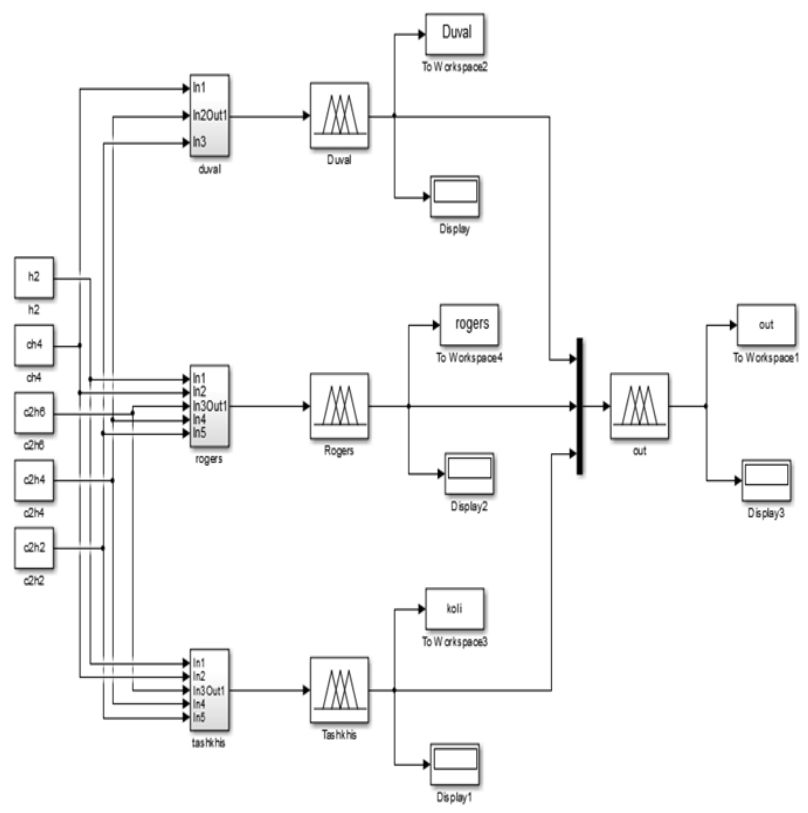

Figure 6. The fuzzy logic detection system designed in Simulink

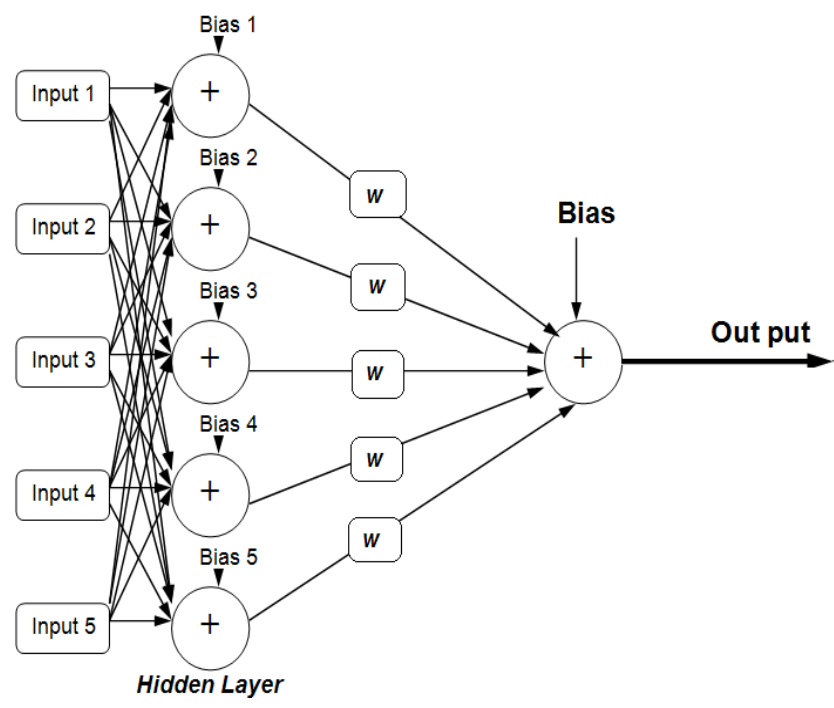

Figure 7. Schematics of designed feed forward neural network

The mathematical approximated formula is obtained using mathematical relations and tuned weights of the neural network as below:

$$
\begin{aligned}
& y=\log \left[9.057 x_{1}+0.694 x_{2}+0.491 x_{3}+1.833 x_{4}+\right. \\
& \left.1.261 x_{5}-3.2\right]-3.5
\end{aligned}
$$

Where $x 1$ to $x 5$, respectively illuminate $\mathrm{h} 2, \mathrm{CH} 4, \mathrm{C} 2 \mathrm{H} 6$, $\mathrm{C} 2 \mathrm{H} 4$ and $\mathrm{C} 2 \mathrm{H} 2$ values; y represents the output of the fuzzy system of internal transformer error after DGA diagnostic process, and interpreted according to Figure 5.

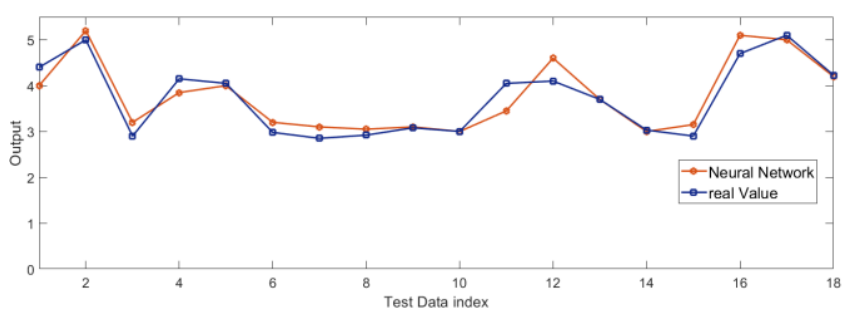

Figure 8. Comparing between the real test values and the output values predicted by the feed forward neural network (test data).

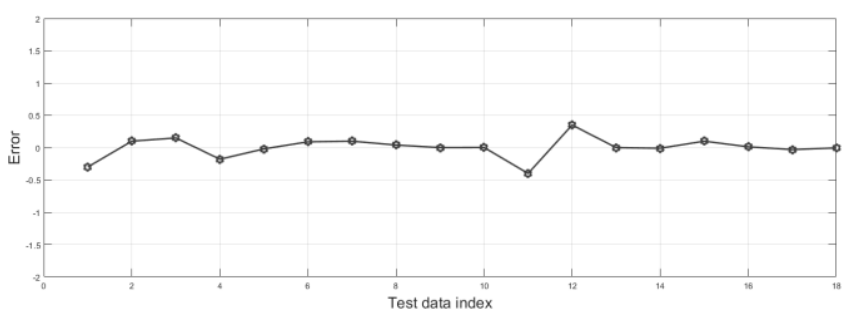

Figure 9. Neural network error comparing with real test data

\section{RESULTS}

After preparation and compilation process, the software was tested with data set consist of 80 different real conditions of oil immersed power transformers, and the results were compared with manual calculations. The data used for samples were collected from transformers oil under different conditions. A summary of the results as an appraisal analysis of the program is presented in Table 6 . Table 6 demonstrates the prediction result of transformer fault status considering four commonly used diagnostic methods comparing with proposed alternative algorithm. Five gas samples obtained from 80 real power transformers are used to check the correctness of internal estimated fault.

\section{DISCUSSION}

Examining the results and comparing with the actual results we get that in cases where the values of gases are near the boundaries determined by the Duvall triangle model, the Duvall method is wrong and cannot properly detect these errors due to the absence of normal operation mode of transformer. And this may cause wrong the transformer interruption and also lessen the popularity of 
the Duval triangle method. On the other hand, Rogers's method also indicates that an unknown or out-of-range error is present in some cases when the ratios are not in its range. Due to these problems, it was tried to provide a method that improves the performance of the dissolved gases analysis, thus combining two popular methods, Duval triangle and Rogers's ratios. We also added the fuzzy logic inference engine to increase the efficiency of the proposed method. It is also approximated using proper neural network and the obtained mathematical formula is easily useable in the common electrical industry analysis software. It was showed that the proposed fuzzy inference engine increases the performance of diagnostic methods and reduces error in DGA process. Furthermore normal condition status is applicable in this proposed method.

Table 5. DGA results and proposed fuzzy logic model output

\begin{tabular}{|c|c|c|c|c|c|c|c|c|c|c|}
\hline Sample & $\mathbf{H}_{2}$ & $\mathrm{CH}_{4}$ & $\mathrm{C}_{2} \mathrm{H}_{6}$ & $\mathrm{C}_{2} \mathrm{H}_{4}$ & $\mathrm{C}_{2} \mathbf{H}_{2}$ & Duval & $\begin{array}{l}\text { Duval } \\
\text { Fuzzy }\end{array}$ & Roger & $\begin{array}{l}\text { Roger } \\
\text { Fuzzy }\end{array}$ & $\begin{array}{c}\text { FUZZY } \\
\text { (Proposed) }\end{array}$ \\
\hline 1 & 200 & 205.9 & 250 & 740 & 1 & T3 & T3 & U.T & K700 & T2K700 \\
\hline 2 & 300 & 112.25 & 180 & 360 & 95 & DT & DT & U.T & HED-LTT & D2HED \\
\hline 3 & 56 & 334.1 & 75 & 32 & 31 & DT & DT & U.T & HED-LTT & D2HED \\
\hline 4 & 33 & 7.882 & 6 & 5.3 & 0.2 & $\mathrm{~T} 2$ & $\mathrm{~T} 2$ & NORMAL & NORMAL & NORMAL \\
\hline 5 & 176 & 652.9 & 47.7 & 75.7 & 68.7 & DT & DT & U.T & HED-LTT & D2HED \\
\hline 6 & 70.4 & 198.9 & 28.9 & 241.2 & 10.4 & $\mathrm{~T} 3$ & T3 & B700 & B700 & T3B700 \\
\hline 7 & 162 & 21.92 & 5.6 & 30 & 44 & D2 & D2 & PD & HED & D2HED \\
\hline 8 & 345 & 37.6 & 27.5 & 51.5 & 58.75 & $\mathrm{D} 2$ & $\mathrm{D} 2$ & $\mathrm{PD}$ & HED-LTT & D2HED \\
\hline 9 & 181 & 0.574 & 210 & 528 & 0 & T3 & T3 & U.T & LTT & T2K700 \\
\hline 10 & 172.9 & 205.9 & 172.9 & 812.5 & 37.7 & D1 & T3 & U.T & B700 & T3B700 \\
\hline 11 & 2587.2 & 112.25 & 4.704 & 1.4 & 0 & PD & PD & U.T & LED & PDUT \\
\hline 12 & 1678 & 334.1 & 80.7 & 1005.9 & 419.1 & DT & DT & PD & HED & D2HED \\
\hline 13 & 206 & 7.882 & 74 & 612.7 & 15.1 & T3 & T3 & U.T & HED & T2K700 \\
\hline 14 & 180 & 652.9 & 75 & 50 & 4 & T1 & $\mathrm{T} 1$ & U.T & K700 & T2K700 \\
\hline 15 & 34.45 & 198.9 & 3.19 & 44.96 & 19.62 & DT & DT & U.T & HED-LTT & D2HED \\
\hline 16 & 51.2 & 21.92 & 5.1 & 52.8 & 51.6 & D2 & D2 & PD & HED & D2HED \\
\hline 17 & 106 & 37.6 & 4 & 28 & 37 & D2 & D2 & PD & HED & D2HED \\
\hline . & & & & & & & & & & \\
\hline 78 & 180.85 & 0.574 & 0.234 & 0.188 & 0 & $\mathrm{~T} 2$ & $\mathrm{~T} 2$ & U.T & LED & T2K700 \\
\hline 78 & 27 & 205.9 & 42 & 63 & 0.2 & $\mathrm{~T} 2$ & $\mathrm{~T} 2$ & U.T & K700 & T2K700 \\
\hline 80 & 138.8 & 112.25 & 6.77 & 62.8 & 9.55 & DT & DT & PD & HED & D2HED \\
\hline
\end{tabular}

\section{CONCLUSION}

The proposed alternative diagnostic DGA algorithm model is discussed in details and has was tested using 80 DGA real samples from a set of power transformers installed in Iran. it was observed that in all cases the proposed model which consists of three fuzzy inference engines, detection quality and accuracy factor are enhanced comparing with two previous popular DGA methods.

In continue with utilization of a proper 2-layer feed forward neural network, the transfer function was obtained as a mathematical formula to introduce the alternative proposed method as a simple and user friend concept in DGA .furthermore The proposed model reduces the time to calculate and analyze the oil transformer errors using the DGA system; provides more precise results for the detection of the transformer initiator error, and reduces the human error in interpreting the detection of error in the DGA process.

\section{REFERENCES}

[1] D. R. Morais, "Ferramenta inteligente para detecção de falhas incipientes em transformadores baseada na análise de gases dissolvidos no óleo isolante," 2004.
[2] E. Dornenburg and O. Gerber, "Analysis of dissolved and free gases for monitoring performance of oil-filled transformers," Brown 1 Boveri Rev, vol. 54, pp. 104-111, 1967.

[3] B.Barraclough, E. Bayley, I. Davies, K. Robinson, R. Rogers, and E. Shanks, "CEGB experience of the analysis of dissolved gas in transformer oil for the detection of incipient faults," in IEE Conference Publication 1973.

[4] R. Rogers, "UK Experience in the interpretation of incipient faults in power transformers by dissolved gas-in-oil chromatographic analysis," in Double Conference Index of Minutes, 1975, pp. 10-201.

[5] C. E. Lin, J.-M. Ling, and C.-L. Huang, "An expert system for transformer fault diagnosis using dissolved gas analysis," IEEE transactions on Power Delivery, vol. 8, pp. 231-238, 1993.

[6] R. R. de Aquino, M. M. Lira, T. Filgueiras, H. Ferreira, O. N. Neto, A. M. Silva, et al., "A fuzzy system for detection of incipient fault in power transformers based on gas-in-oil analysis," in Fuzzy Systems (FUZZ), 2010 IEEE International Conference on, 2010, pp. 1-6.

[7] H.-T. Yang, C.-C. Liao, and J.-H. Chou, "Fuzzy learning vector quantization networks for power 
transformer condition assessment," IEEE Transactions on Dielectrics and Electrical Insulation, vol. 8, pp. 143-149, 2001.

[8] T. Committee, "IEEE guide for the interpretation of gases generated in oil-immersed transformers," Institute of Electrical \& Electronics Engineers, Inc., NY, 1992.

[9] M. Duval, "A review of faults detectable by gas-inoil analysis in transformers," IEEE electrical Insulation magazine, vol. 18, pp. 8-17, 2002.

[10] T. M. Barbosa, M. A. F. Finocchio, J. G. Ferreira, and W. Endo, "Development of software based of the Duval Triangle method," in Industry Applications (INDUSCON), 2016 12th IEEE International Conference on, 2016, pp. 1-8.

[11] J. Tang; F. Meng, "An approach to interval-valued intuitionistic fuzzy decision making based on induced generalized symmetrical Choquet Shapley operator", Scientia Iranica journal, pp. 1456-1470, 2018.

[12] M. Najafi, H. Haghighi and T. Zohdi Nasab" A survey on formal, object-oriented program development approaches ", Scientia Iranica journal, pp. 1001-1017, 2015.

[13] M. Amjadzadeh, K. Ansari-Asl," An Innovative Emotion Assessment using Physiological Signals Based on The Combination Mechanism" Scientia Iranica journal, pp. 3157-3170, 2017.
[14] A. Shemshadi, et al., "Dielectric Recovery Process in Vacuum Interrupters Regarding to Contact Materials during Post Arc Interval", IEEE Transactions on Dielectrics and Electrical Insulation, Vol. 22, No. 5; pp. 3059-3064, 2015.

[15] A. Shemshadi, S. Jalali Kashani, "The Requisition of Auto Synchronism for Vacuum Interrupters during Quenching Arc Interval", Latin American Applied Research, Vol. 48, pp. 1-5, 2018. [18]

[18] Tajdinian M, Allahbakhshi M, Seifi A, Bagheri A," Analytical discrete Fourier transformer-based phasor estimation method for reducing transient impact of capacitor voltage transformer", IET Generation, Transmission \& Distribution 11:23242332, 2017.

[19] M. Rahnavard, S. M. H. Alavi, S. Khorasani, M. Vakilian, M. Fardmanesh," Educational Robot for Principles of Electrical Engineering", Scientia Iranica journal, pp. 1582-1592, 2018.

[20] Naseri F, Farjah E, Allahbakhshi M, Kazemi Z," Online condition monitoring and fault detection of large supercapacitor banks in electric vehicle applications", IET Electrical Systems in Transportation, 2017.

[21] M. H. Abdi, N. B. Ibrahim, H. Baqiah, S.A. Halim," Structural, electrical, and magnetic characterization of nickel-doped tin oxide film by a sol-gel method", Scientia Iranica journal, pp. 2459-2467, 2014. 